\title{
ON THE DISSIPATION LAYER OF RADIAL BEARINGS
}

\section{R.O. AYENI, S.S. OKOYA and C.J. AGORZIE}

\author{
Department of Mathematics \\ University of Ife \\ Ile-Ife, Nigeria
}

(Received May 14, 1986)

ABSTRACT. The dissipation boundary layer of certain radial bearings is identified. It is shown that, under certain conditions, the temperature outside this layer is constant.

KEY WORDS AND PHRASES. Dissipation boundary Zayer, variable viscosity, coupled momentwo and energy equations, thin Zubricating oils.

1980 AMS SUBJECT CLASSIFICATION EODE. 80A20.

\section{INTRODUCTION.}

In paper [1], we discussed the solution to the coupled momentum and energy equations

$$
\begin{aligned}
& \frac{\partial \phi}{\partial t}=\operatorname{Pr} \frac{\partial}{\partial y}\left(\exp \left(\frac{\lambda_{1}}{\theta+\lambda_{2}}\right) \frac{\partial \phi}{\partial y}\right) \\
& \frac{\partial \theta}{\partial t}=\frac{\partial^{2} \theta}{\partial y^{2}}-\left(\frac{\partial \theta}{\partial y}\right)^{2}+\Delta \exp \left(\theta+\frac{\lambda_{1}}{\theta+\lambda_{2}}\right)\left(\frac{\partial \phi}{\partial y}\right)^{2}
\end{aligned}
$$

where $\lambda_{1}, \lambda_{2}$ and $\Delta$ are constants.

The boundary and inftial conditions are

$$
\begin{aligned}
& \frac{\partial \phi}{\partial y}(0, t)=-\frac{B}{\sqrt{t}} \cdot \phi(0, t) \text { given, } \phi(\infty, t)=0 \\
& \phi(y, 0)=0 \\
& \theta(0, t)=\theta(\infty, t)=0 \\
& \theta(y, 0)=0
\end{aligned}
$$

The above equations arose from investigations on the flow of thin lubricating oils.

Earlier in [2], we discussed the thermal runaway of variable viscosity flows between concentric cylinders - there is a wide gap between the cylinders and we show that, under certain conditions which affect the Peclet number, the reduced Reynolds number and the Nahme-Griffith number, the width of the thermal boundary layer is $0(R)$ where $R$ is the radius of the inner cylinder. Under the same assumptions, there exists a dissipation boundary layer of width $0\left(R / G^{2}\right)$ where $G$ is the Nahme-Griffith number.

In the case of radial bearings, the width, $h$, of the lubricant is small and thus if $R_{1}, R_{2}$ are the radii of the shaft and the bearing then

$$
R_{i}>h . \quad i=1,2
$$


(1.7) implies that as a first approximation, we may regard the shaft and the bearing as flat surfaces, that is $R_{i} \rightarrow \infty$ when $h$ is the standard measure. We therefore need to investigate the boundary layer of the lubrication problem although $0\left(\mathrm{R} / \mathrm{G}^{2}\right)$ is adequate for [2].

2. DISSIPATION BOUNDARY LAYER.

Shampine [3] investigated the problem

$$
\begin{aligned}
& \frac{\partial c}{\partial t}=\frac{\partial}{\partial x}\left(D(c) \frac{\partial c}{\partial x}\right), \\
& c(0, t)=1, \frac{\partial c}{\partial x}(0, t), \text { given }
\end{aligned}
$$

He showed that if

$$
-D(1) \frac{\partial c}{\partial t}(0, t)=\frac{1}{2}+\max D(c),
$$

then there is an $n_{1}<1$ such that $c\left(n_{1}\right)=0$, where $n=x / \sqrt{t}$. For the proof of this, see [3].

In this paper as in [1], we have

$$
\operatorname{Pr} \exp \left(\frac{\lambda_{1}}{\theta+\lambda_{2}}\right)
$$

in the plane of $D(c)$ above, but a careful study of the proof advanced by Shampine showed that his result is true for (1.1). That is, there exists an $\eta_{1}<1$ such that if

$$
B=1+\frac{1}{2} e^{-\frac{\lambda_{1}}{\lambda_{2}}}
$$

then there exists an $n_{1}<1$ such that $\phi\left(n_{1}\right)=0$ and $\phi(n) \equiv 0$ for $n \geq n_{1}$. This leads to

THEOREM. Let $(1.1),(1.2)(1.3)-(1.6)$, and (2.3) hold. Then there exists an $n_{2} \leq 1$ such that $\theta\left(n_{2}\right)=0$ and $\theta(n) \equiv 0$ and $n \geq \eta_{2}$.

PROOF. $\phi\left(n_{1}\right) \equiv 0$ for $n \geq n_{1}$

implies $\frac{\partial \phi}{\partial y} \equiv 0$ for $n>n_{1}$.

That is, $\frac{\partial \phi}{\partial y} \equiv 0$ for $n \geq n_{2}=n_{1}^{+}$

Hence $\quad \theta \equiv 0$ for $n \geq n_{2}$.

3. PHYSICAL INTERPRETATION.

The above theorem shows that at time $t$ the heat generated has only penetrated to $y=n_{2} \sqrt{t}$. This identifies the dissipation layer. The viscosity of the lubricant outside this layer is not affected by heat under the conditions assumed in this problem.

\section{REFERENCES}

1. AYENI, R. 0. AKINRELERE, E. A., and AMAO, J. 0., On the Temperature of Radial Bearings - I, Matematika 32 (1985), 317-324.

2. AYENI, R. 0 . On the Thermal Runaway of Variable Viscosity Flows Between Concentric Cylinders, Z. Angew. Math. Phys. 33(1982), 408-413.

3. SHAMPINE, L. F. Concentration-dependent Diffusion II. Singular Problems, Quart. App1. Math. 31 (1973), 287-293.

4. SHAMPINE, L. F. Concentration-dependent Diffusion, Quart. App1. Math. 30 (1973), 441-452.

5. WAGNER, C. Diffusion of Lead Chloride in Solid Silver Chloride, J. Chem. Phys. 18 (1950), 1227-1230. 


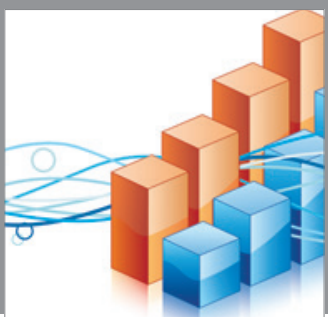

Advances in

Operations Research

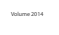

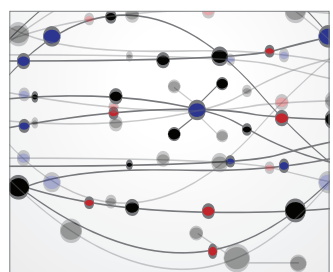

\section{The Scientific} World Journal
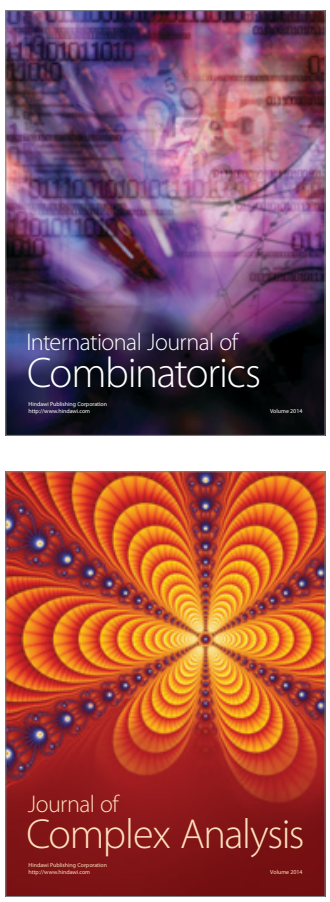

International Journal of

Mathematics and

Mathematical

Sciences
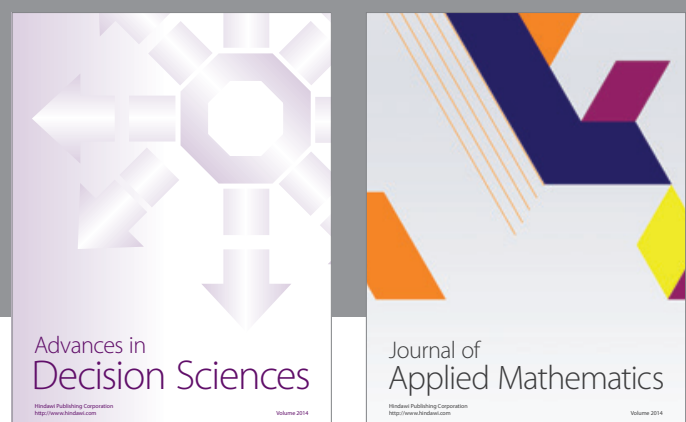

Journal of

Applied Mathematics
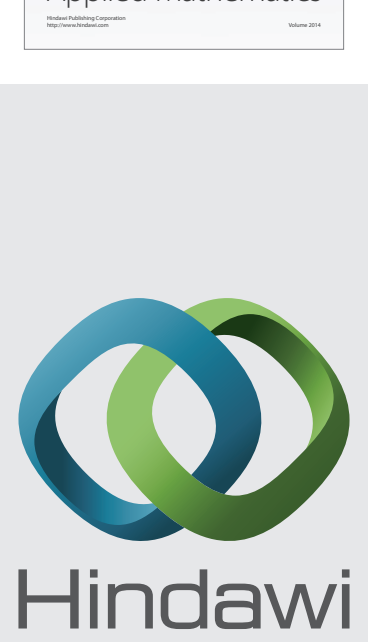

Submit your manuscripts at http://www.hindawi.com
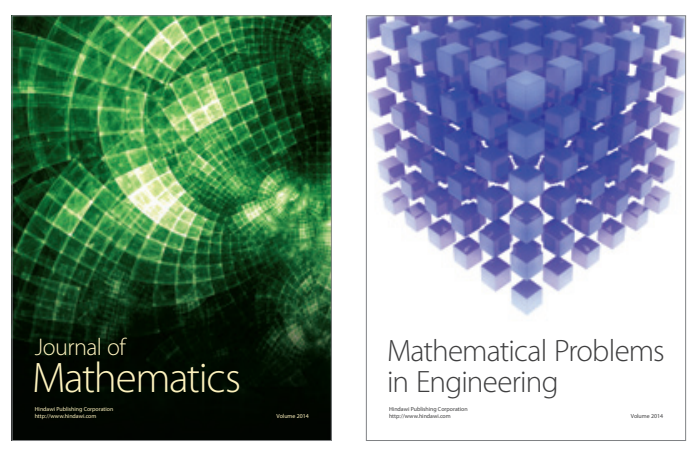

Mathematical Problems in Engineering
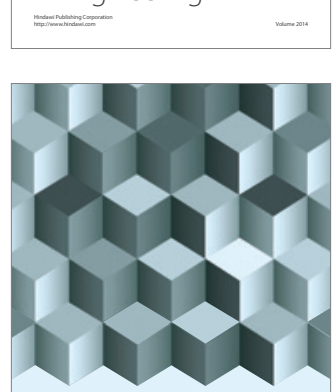

Journal of

Function Spaces
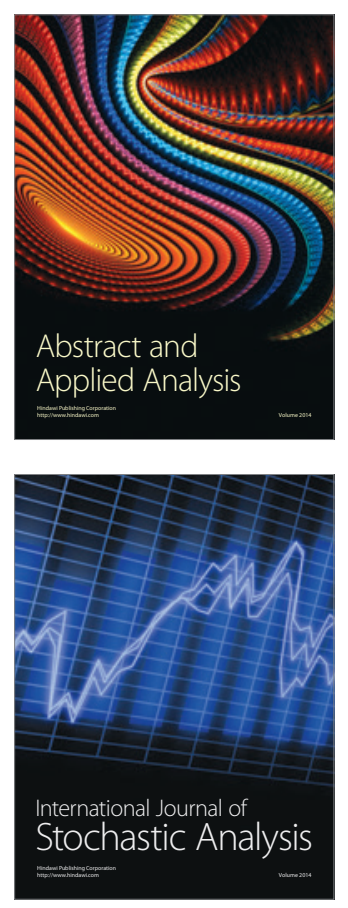

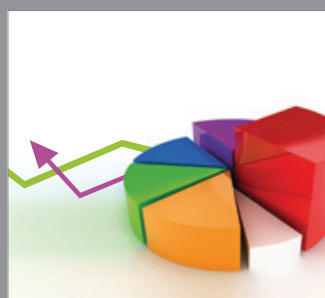

ournal of

Probability and Statistics

Promensencen
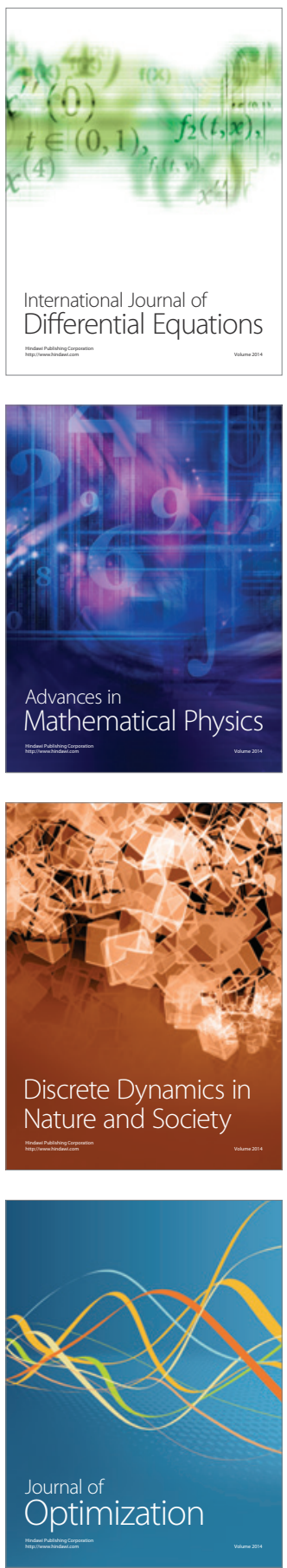